\section{ON THE COLOURING-MATTERS FOUND IN FUNGI}

D URING the last autumn I studied very carefully the colouring-matters occurring in such fungi as I was able to find in my own district. For the correct specific determination of many of them I am much inbebted to Mr. M. C. Cooke. Though the number examined was small, compared with the total number of British species, it was sufficient to lead to some interesting conclusions, and at the same time to point out the necessity of the examination of many more, which so far have not fallen under my notice. It therefore appears to me better to postpone the description of the individual colouring-matters until I can include a greater number, and compare them as a whole with those found in algæ, lichens, and other natural orders; but at the same time it may be well to give a short general account of some of the conclusions to which I have been led by the facts already observed.

So far I have been able to determine, by means of their optical and other properties, the existence of at least thirty distinct colouring-matters, and I feel persuaded that further examination will greatly extend the list. The majority of fungi contain at least two, and many contain several, different coloured substances, which can be separated, or perfectly well distinguished by other means. Closely allied species sometimes contain two or more in cornmon, but very often one or more differ ; whilst, at the same time, species belonging to somewhat widelyl separated genera are occasionally coloured by identical substances-for example, Stereum hirsutum andPeziza aurantia. Notwithstanding this, on the whole, there does appear to be a very. decided connection between the general organisation of the plant and the particular kind of colouring-matter developed in it. There is, however, a considerable variaation, even in different individuals of the same speciesone developes much of one substance, and another of another-and thus we can easily understand why we often find them of very different colours, with every intermediate tint. The connection between general organisation and the coloured products is still more decidedly proved by comparing those met with in fungi with those found in other natural orders. As already mentioned, I have been able to distinguish at least thirty different kinds in fungi, Of these fully twenty have such wellmarked optical characters that they could be recognised without difficulty in other plants. Some of therest could not be easily distinguished when mixed with any of the modifications of tannic acid, and therefore nothing very positive can be said about their presence or absence in certain plants. Confining our attention to those about which there is no such doubt, I may say that only one is known to occur in any plant not a fungus. This is the fine orange colour, soluble in bi-sulphide of carbon, found in Calocera viscosa, which agrees perfectly with the more orange-coloured xanthophyll of some faded leaves, and of the exterior layer of the root of the carrot. The rest have hitherto been found only in various fungi. Neglecting individual differences, and taking into consideration only such general characters as are most useful in dividing colouring-matters into hatural groups, there is also a remarkable difference between those of fungi and of some other natural orders. In several previous papers I have described how colouring-matters may be divided into three groups by the manner in which they are acted upon by sulphite of soda. In group $A$ the detached absorption is removed, even when the solution contains free ammonia; in group $B$ it is removed only when the solution contains excess of a weak acid, whilst group $C$ is not changed in either case. So far, with only two exceptions, all the colouring-matters found in fungi belong to group $C$, even when they are blue or red, whereas with only two exceptions all the blue and red colouring-matters in the petals and leaves of flowering plants belong to groups $\mathrm{A}$ and B. A larger proportion of those of group $C$ occurs in fruits, and a still larger in coloured woods, and thus the colouring-matters of fungi are much more closely related to those in woods than to those in flowers or leaves. As far as my observations extend, there is little or no specific agreement between the substances found in fungi and those in algæ and lichens. These latter orders are, however, closely related. in this respect, for the greater part of the specific colouring-matters found in algæ occur in lichens, along with others similar to, but perhaps not identical with, those met with in fungi. Substances analogous to tannic acid are not of common occurrence, but are found in a few, as for example in Agaricus sublateritius, passing by oxidisation into a very insoluble brown colouring-matter, as in the case of faded leaves in autumn.

I am most willing to admit that much still remains to be learned; but, at the same time, these various facts appear to prove that there is some definite rel tion between the organisation of plants and the chemical and optical characters of the compounds formed during their growth. If further research should establish this conclusion, one may perhaps indulge the hope that it will throw much light on certain questions in vegetable physiology.

H. C. SORBY.

\section{SCHMIDT'S COMPARATIVE ANATOMY}

Handbuch der Vergleichenden Anatomie. Eduard Oscar Schmidt. Sechste Auflage. (Jena, 1872.) Pp. 402.

$\mathrm{T}$ is now more than twenty years since the first edition 1 of this manual appeared. The plan is that of a companion to the author's lectures as Professor in the University of Gratz. It begins with a somewhat lengthy introduction on the general principles of Morphology and Physiology. In discussing the distinction between animals and plants, the author appositely quotes Buffon's dictum, "Il n'y a aucune différence absolument essentielle et générale entre les animaux et les végétaux." He also does full justice to the pre-eminent importance of Cuvier's labours in palæontology as well as in comparative anatomy and classification; but it is strange to find the name of Hunter conspicuous by its absence, even in a brief sketch of scientific biology. The lines which the author has chosen for the motto of his book,

Alle Gestalten sind ähnlich, und keine gleichet der andern,

Und so deutet der Chor auf ein geheimes Gesetz,

have, he believes, now received their solution. For Prof. Oscar Schmidt is a convert to the Darwinian creed. He says, "I have not freed myself from my old geological orthodoxy without much difficulty; and I am therefore 